\title{
FEMININE VS. MASCULINE GESTURAL MARKETING. CASE STUDY: THE FRENCH PRESIDENTIAL DEBATE ON MAY 2, 2007
}

\author{
Brînduşa-Mariana Amălăncei \\ "Vasile Alecsandri” University of Bacau \\ brandusa_amalancei@yahoo.com
}

\begin{abstract}
The gestures of presidential candidates can have an important contribution to the shaping of their mediatized image, together with the other components of nonverbal communication as well as together with words. Even more, gestures can have an impact on the evaluation made by a part of the electorate concerning the candidates. Starting from the functions of gestures in which the raised index finger is involved, as established by Geneviève Calbris (1979), we will endeavour to conduct a comparative analysis of the co-verbal gestures made by the two candidates to the presidency of France, Ségolène Royal and Nicolas Sarkozy, during their debate on May 2 2007. The identification of these functions does not include the gestures made with the index finger in combination with other facial components, as well as the gestures where the index finger describes lines drawn in space. The article uses as a research method the contents analysis of these gestures and is based on a scheme of categories that comprises the following indicators: designation/localization, important declaration, (drawing) attention to oneself, uniqueness, reference, refusal/negation, opposition/objection, threat/warning, or accusation.
\end{abstract}

\section{Keywords}

gestures; impact; image; the presidential debate; the functions of the index finger

\section{JEL Classification}

M37

\section{Introduction}

The French presidential debate that took place on May 2, 2007 brought Ségolène Royal and Nicolas Sarkozy face to face. Prior to this debate, during the entire electoral campaign, both of them had adopted the image of the person who succeeded in life unaided (self-made man/ woman). Thus, their campaign speeches revealed the present suffering of the electorate as similar to the past difficulties of the candidates: the troublesome childhood, the hard career debut, the failed first marriage etc. The candidates identified themselves with the suffering citizens but, at the same time, distinguished themselves from them due to the fact that they had managed to overcome their distress. The individual success the electors could identify themselves with represented the essence of this typical character, which is attainable only through personal merit, courage, energy, and tenacity. Ségolène Royal insisted on her ability of having prevailed over the difficulties of her condition as a woman. Due to her qualities, she managed to combine her family life with her public life, to evolve in a political environment considered to be manly and to overcome the troubles caused by the ironic remarks concerning her competences. In effect, in the official campaign show broadcast on May 2, 2007, Ségolène Royal presented herself as a strong woman and a fighter who wanted to lead the French towards victory. For Nicolas Sarkozy, to 
succeed meant having the capacity to overcome suffering, as well as being able to live with it. His chief merit was, therefore, that of having the courage to triumph over failure, as well as his aptitude of dominating his suffering and of making it serve his ambition (Ballet, 2014).

Christian Delporte (2012) offers details regarding the manner in which the presidential debate was prepared. Transmitted by the French television channels TF1 and France 2, the debate was produced by a well-known specialist from the area of political programs, Jérôme Revon, was moderated by Arlette Chabot (France 2) and Patrick Poivre d'Arvor (TF1), lasted 2 hours and 40 minutes and took place in the SFP studios of Boulogne, in a studio setting of 200 square meters.

The socialist candidate, Ségolène Royal, prepared in her campaign studio. The discourse forms and the language tics of her adversary were analysed, and the manager of the advertising agency Ogilvy \& Mather France advised her regarding the ways of expressing and behaving, insisting on the idea of calmness, concentration and self-restraint in communication. Ségolène Royal also asked her campaign team to prepare questions that could destabilize her interlocutor.

In his turn, Nicolas Sarkozy gathered his political collaborators at a hotel in Corsica, including a socialist official, who had recently joined the opposite party and who knew Royal's weak points quite well and could thus advise him on how to exploit them to the disadvantage of his adversary. Sarkozy's campaign team analysed the most recent televised debates where the socialist candidate was invited. For Sarkozy, who had occupied the first position in opinion polls since the middle of January, the risks were very high and he had to show that the duel on May 2 represented only a stage in his campaign. Given this reason, he insisted on being present the morning of the debate on France-Inter, where he tried to minimize the importance of the duel, claiming serenely that the French do not choose the president of the Republic according to the impression they form after a three-hour debate, even if this debate is important.

In fact, the presidential debates of 1981, 1988 and 1995 did not influence the results of the final vote either and four days before the decisive vote $87 \%$ of the electorate stated that they had already decided whom to vote. However, his campaign team feared that Nicolas Sarkozy might seem too brutal for the viewers given that his adversary was a woman.

The two counter candidates were thus advised to be neither too calm nor too aggressive. Even if both of them were accustomed to television studios, Nicolas Sarkozy had, in Christian Delporte's view, the unquestionable advantage of over fifteen years of personal experience in confronting adversaries on television, a type of experience that made him 'sparkle' in such meetings. On the other hand, for Ségolène Royal the presidential campaign represented the moment in which she discovered the polemical debate. As a result, her oratorical qualities were modest but she could make use of the advantages her supporters appreciated, namely, sincerity and humaneness.

\section{The importance of gestures for building one's mediatized image}

The gestures of the two candidates to the presidency of France (especially Nicolas Sarkozy's gestures) employed during the presidential debate of May 2, 2007 represented a topic of investigation for Riham El Khamissy (2010), who claims that Sarkozy's victory was particularly the result of the gestural image built during his mediatized appearances. Riham El Khamissy believes that the outward look and gestures of a candidate become as important as his words in the case of televised shows, the quality of being telegenic and charisma being attributes that can contribute 
to the winning of elections. In general, the significance of bodily movements is often revealed by contextual factors (space-time, gesticulator, receiver of the gesture and the word that accompanies it), the words and gestures highlighting their expressiveness reciprocally. The analysis of Nicolas Sarkozy's gestures from a pragmatic perspective is considered by the author mentioned above, whose opinion we share, as being the most adequate one for the study of the influence exercised by a candidate on the viewers by means of the outward look and the co-verbal gestures in a determined context.

Riham El Khamissy followed the model offered by Geneviève Calbris, who investigated a corpus of six televised shows that had Lionel Jospin as a protagonist, during his prime ministership of France. The study started mainly from the assumption that the recurrence of certain gestures can constitute a clue related to what the gesticulator thinks (Calbris, 2003). Therefore, by means of his gestures, Sarkozy showed, in Riham El Khamissy's view, precision and concision (by using the vertical circle made with the thumb and the index finger or the vertical digital tweezers, both being considered gestures indicating rigour), clarity in thinking (by employing gestural enumeration), combativity (by raising the closed fist) and responsibility (by a self-referential gesture with the hand, with or without touching; El Khamissy, 2010).

Guy Barrier (2011) also dealt with the analysis of the two candidates' gestures and he observed that Nicolas Sarkozy was more expansive gesturally than his counter candidate, who used the table as a background of expression for her movements. As far as their posture was concerned, Ségolène Royal's bearing was more upright and more stable, whereas Nicolas Sarkozy continuously moved his chest sideways. Ségolène Royal repeatedly placed her left hand on top of her right hand, as François Mitterrand used to do, and her gestures were very discreet until they started debating the issue of disabled children in schools. At that point she started to make indicative gestures with her index finger or 'chanted' prosodic gestures combined with a facial expression that transmitted anger. Even though her adversary tried to control his pitch, his state of discomfort was indicated by his facial expression (a contracted forehead, raised eyebrows, frequent winking) and by constantly looking down while speaking.

We will further attempt to interpret the co-verbal gestures made with the raised index finger by the two candidates during the debate. Our approach is based on the contents analysis of these gestures by making reference to the functions that can be associated with them with the aim of supporting the verbal sequences with which these particular gestures are correlated.

Contents analysis represents, from a sociological perspective, "that specific research method which allows the making of inferences by means of the systematic and objective identification of specific characteristics in a text" (Chelcea, 2001) or, from a broader perspective, it can be considered a system for decoding messages, a "technique that aims at describing, with optimal objectivity, precision and generality, what is said about a given subject, in a specific space, at a certain moment" (Agabrian, 2006).

The objective of our analysis is thus to highlight the functions of gestures made with the raised index finger, on the basis of the model originally discussed by Geneviève Calbris (Calbris, 1979), with special focus on the frequency of these gestures made by the participants to the debate in different contexts and, secondly, with regard to the fact that the exaggerated use of the accusatory index finger by Ségolène Royal during the "anger scene" made Nicolas Sarkozy retort ("Calm down and do not point your finger at me!”; source: http://www.dailymotion.com/video/xqid78_2007-le-debat- 
segolene-royal-et-nicolas-sarkozy_news). When identifying these functions, Calbris excludes the gestures made with the index finger in combination with component parts of the face (as, for instance, the index finger raised vertically to the mouth to call for quietness), as well as the pointer finger describing lines in space. Thus, the index finger is employed in communication with the following roles: concrete or abstract designation or localization, expressing an important declaration, drawing attention toward the self, expressing uniqueness, specifying by means of restriction or addition, expressing refusal-negation or opposition-objection, or threat-warning. To these we can add the role of making accusations with the index finger.

The functions of the index finger were established by Calbris on the basis of two converging approaches, which allowed data confirmation, addition to the data and, sometimes, their reciprocal interpretation: a research in which illustrations were associated with a scriptural-graphic message revealing a signification and a test in which, starting from a photographed gesture, the participants interpreted freely its possible significations. More precisely, six partial photographs were selected, with isolated gestures, obtained by cutting them from the global images. The photographs presented the raised index finger without touching the face and the gestures corresponded to different situations: indicating direction ("upward"), indicating quantity ("one”), requesting the turn to speaking or asking for permission ("please”/ "if you would be so obliging"), demanding attention ("listen"), indicating a threat ("be careful!") and a refusal ("no”). The last two gestures distinguish themselves from the others by their repeated backward and forward movement or up and down movement suggesting threat and left-right suggesting refusal.
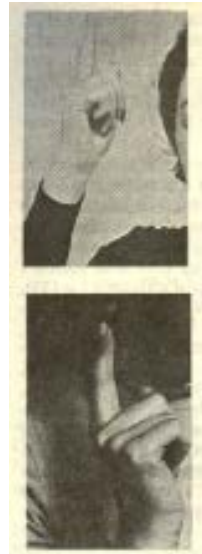

Illustration 1. Gestures made with the index finger

Source: Calbris, G., (1979), L'index signifiant, in Études de linguistique appliquée. Mélange de didactique des langues, no. 35, juillet-septembre, Didier Érudition, Paris, p. 98

Concrete or abstract designation or localization. Oriented toward the exterior, the index finger functions as an instrument which designates a person or an object, the meaning depending on the situation. For instance, depending on the situation and the mimicry it determines, the same gesture with the index finger pointing at a third person, with the implication "he's the one", can correspond to a neutral information, an order, a positive attitude of admiration or a negative attitude of accusation. Likewise, the index finger can be used to designate an animate being, whether a human being or an animal, as well as a concrete or abstract object (a forgotten word or idea). As far as localization is concerned, the index finger can indicate a point, a line, a plane, a certain volume etc. The index oriented toward the east signifies, for 
example, "to the right”, "that way”, whereas its orientation toward the north suggests "forward", "ahead"; oriented downward it means "here".

Important declaration. The index finger raised above the head or at the level of the head accompanies a prophetic, solemn or important declaration and stresses discourse segments, thus cadencing words, imposing the message and highlighting certain elements. The importance of the message for the speaker can be rendered by means of his/her willingness to insist or to bring in supplementary or restrictive information.

Drawing attention to oneself. The index finger raised for a moment above or at the head level also represents a method used for drawing attention to oneself. The gesture is used in different situations to call for a taxi or a waiter, to demand the turn to speaking or to ask for permission to go out etc. The height to which the index is raised and the force with which the gesture is made express the degree of confidence related to the person who wants to attract attention.

Expressing uniqueness. The raised index with the palm commonly oriented toward the self and the nail oriented toward the exterior constitute the symbolical representation of number one, the gesture being used as a means of insisting or specifying.

Specifying by means of restriction or addition. The index finger raised from the chest level frontward, more or less vertically, can be used in order to restrict (commonly in correlation with "just”, "it is only...”, "yes, but...” etc.) or to amplify (correlated with "in addition”, "and”, “all the more” etc.)

Refusal-negation and opposition-objection. In order to express refusal-negation, the index finger is shaken transversally, from left to right. The origin of this gesture lies in stretching the arms on both sides of the body with the aim of obstructing someone's passing. Opposition-objection is indicated by means of the index finger suddenly raised backward, similar to the movement backward made when we want to protect ourselves from a physical attack, simultaneously using our hands in defence.

Threat-warning. The index finger which seems to be directed most diagonally (the last image in the series of six above) was correlated mostly with threat or warning (13 answers out of 28). This position of the index finger sends to the diagonal plane formed by a hand which seems ready to slap.

Accusation. The index directed toward a person can be used as an accusatory gesture, unconsciously provoking negative emotions.

For the quantitative measurement of the gestures made with the index finger by the two candidates we employed a framework for analysis that delimits the functions of these gestures in the discursive sequence. The quantitative analysis was carried out on the basis of the frequency of the gestures and involved the following aspects:

- Numbering the occurrence of gestures included in the categories scheme in order to determine total visibility;

- Numbering occurrence of gestures on each level of the categories scheme, with regard to the two actors.

To this end, the categories scheme we intend to monitor includes the following indicators:

- designation/localization;

- important declaration;

- drawing attention to oneself;

- uniqueness;

- $\quad$ specification;

- refusal/negation;

- opposition/objection; 
- threat/warning;

- accusation.

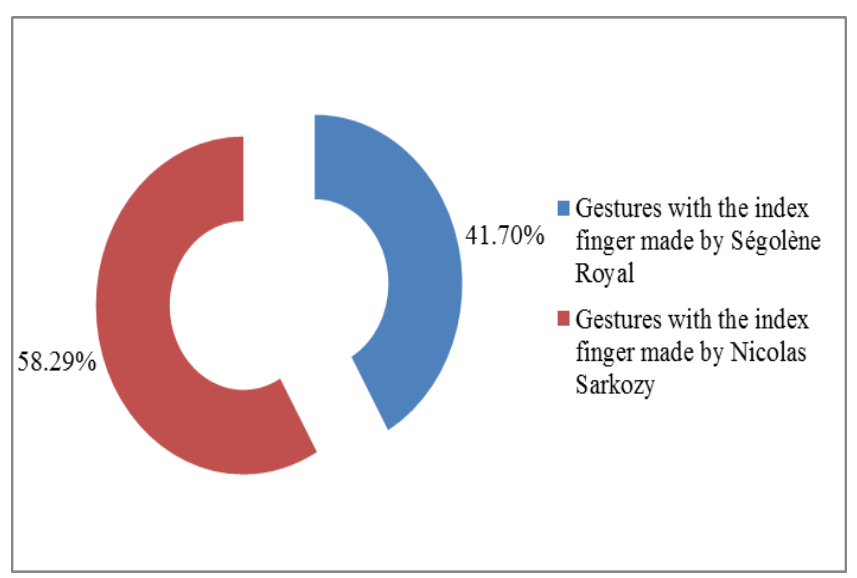

\section{Figure 1. Gestures with the index finger made by Ségolène Royal/ Nicolas Sarkozy}

In the course of the entire debate we identified a total number of 199 gestures with the index finger, 83 made by Ségolène Royal and 116 made by Nicolas Sarkozy. This fact shows a much higher percentage in the case of the masculine candidate, who accumulates $58.29 \%$ in comparison with $41.70 \%$ in the case of the feminine candidate.

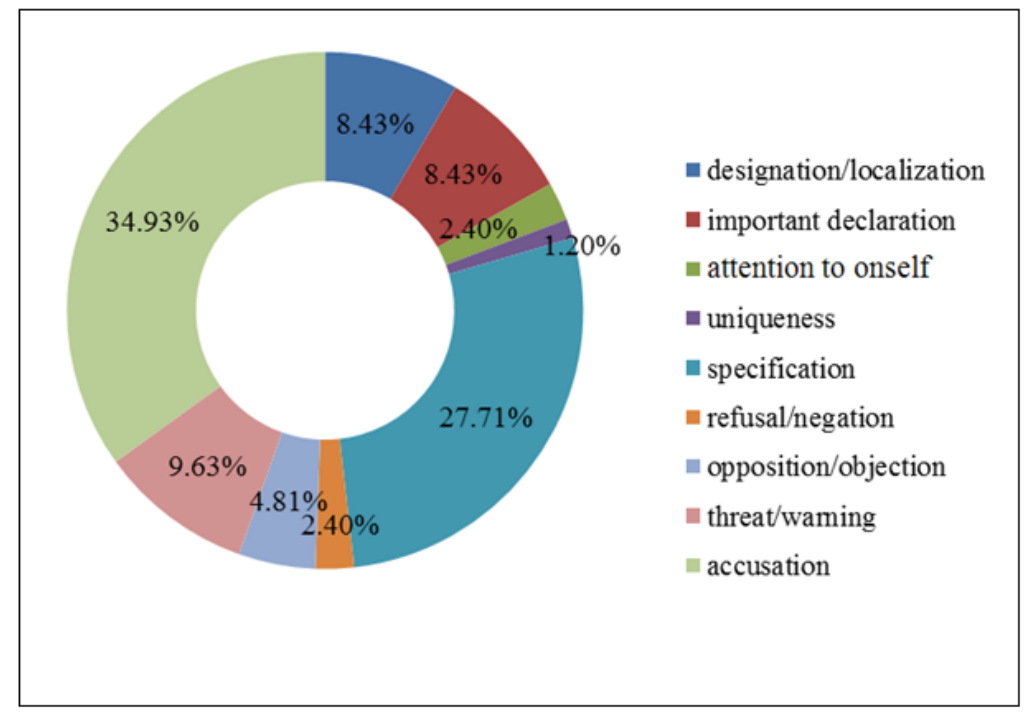

Figure 2. Gestures with the index finger made by Ségolène Royal

The distribution of gestures with the index finger for the feminine candidate reveals major differences in percentage, with Royal amassing a significant percentage, 
especially for accusation (34.93\%), specification (27.71\%) and threat/warning (9.63\%).

This aspect indicates the predominant combative nature of the candidate, who tries, by means of gestures with a negative connotation, to face the confrontation with a masculine candidate successfully. The equal distribution of $8.43 \%$ for the indicators designation/localization and important declaration unfolds the concreteness of Ségolène Royal's gestural expressiveness who, when transmitting an important message, makes use of localization, thus attempting to fix the information in the receiver's mind.

The other types of gestures score a low percentage, but we must observe that in Royal's case we can identify all the functions of these gestures: $4.81 \%$ for opposition/objection (a relatively low percentage compared to the percentage obtained for accusation and threat/warning, a fact which suggests that Royal did not intend to be aggressive with her counter candidate, but only tried to face the confrontation with him successfully), $2.40 \%$ for refusal/negation and attention to oneself and $1.20 \%$ for uniqueness.

These low percental values can be a proof of the fact that Ségolène Royal did not want to present herself in front of Nicolas Sarkozy as a female candidate, who could have been expected to show certain delicacy in terms of gestural expression, but more likely as an adversary that was equal to her counter candidate.

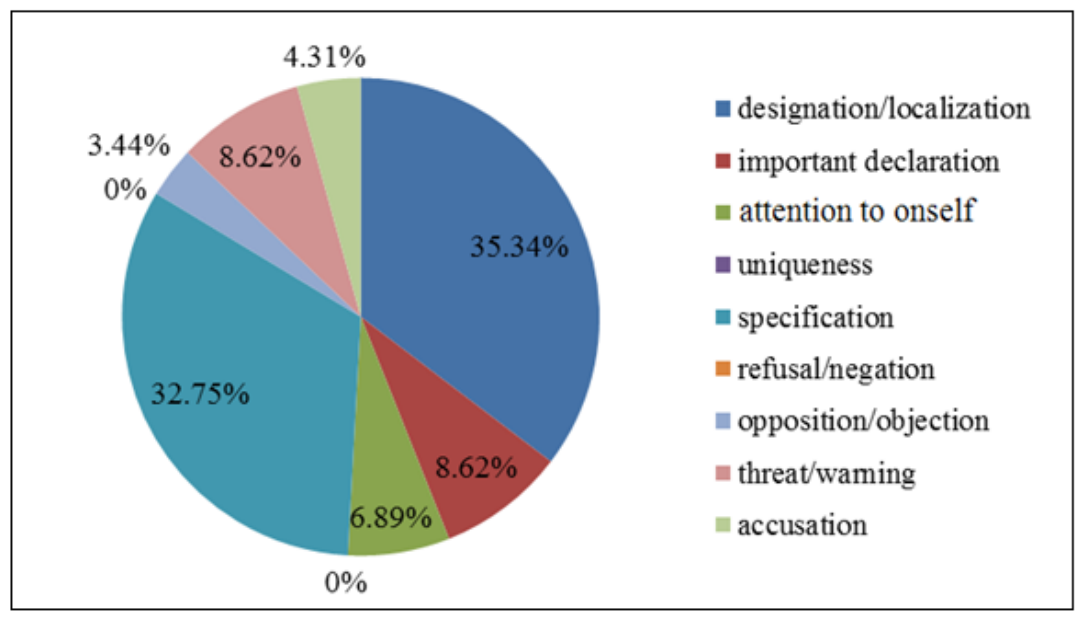

Figure 3. Gestures with the index finger made by Nicolas Sarkozy

The distribution of functions associated with gestures made with the index finger by Nicolas Sarkozy highlights a clear difference, with $35.34 \%$ for designation/localization and $32.75 \%$ for specification, which demonstrates the prominent affirmative character of gestural expressiveness. An equal percentage of $8.62 \%$ was identified in the case of important declaration and threat/warning. The equal distribution of the two functions reveals a certain connection between them, meaning that the important declarations are sometimes backed by threats/warnings, thus maintaining a balance in exploiting affirmative or negative connotations.

Drawing attention to oneself records in Sarkozy's case a much better percental value of $6.89 \%$ as compared to his counter candidate, who recorded a value of $2.40 \%$, a fact which can reveal the politician's attempt to highlight the inequality between them. 
The functions of gestures with negative connotations, namely, accusation (4.31\%) and opposition/objection (3.44\%) are less frequently found in Sarkozy's case, who probably avoids to leave the impression of a direct attack on his counter candidate, a situation in which she could have appeared as being victimized.

We observe in Sarkozy's case the absence of gestures with the function of refusal/negation and uniqueness, these indicators lacking percental results, a fact which confirms once more his intention of not standing out by marking gender inequality.

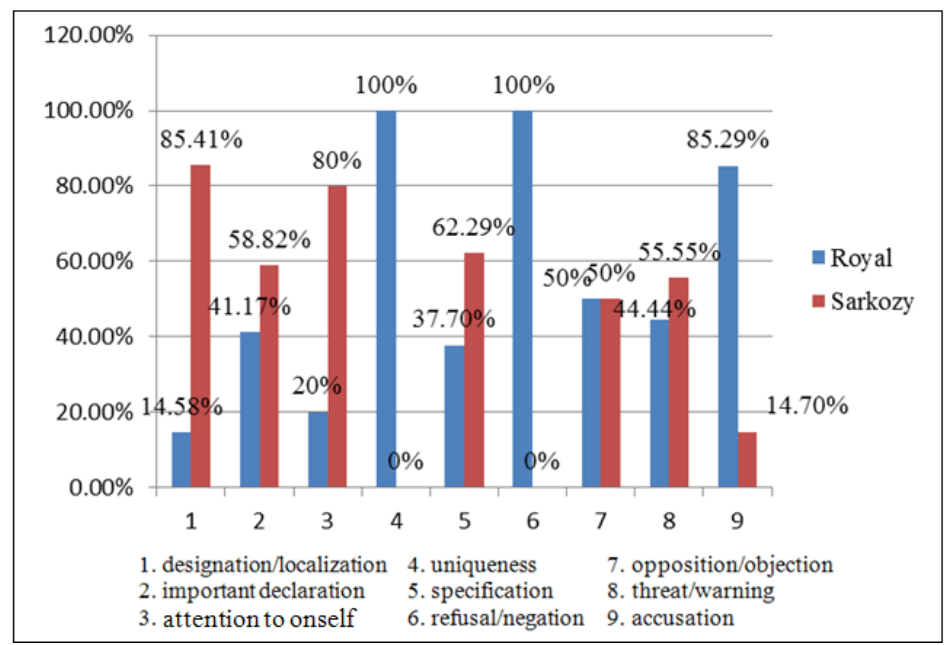

Figure 4. The distribution of functions of gestures with the index finger made by the two counter candidates

The comparative analysis of the two counter candidates reveals a different employment of functions of gestures made with the index finger. Thus, Nicolas Sarkozy employs these gestures more commonly for designation/localization (85.41\%), whereas Ségolène Royal, who displays a more combative nature, predominantly employs accusations (85.29\%).

Opposition/objection is equally distributed, both participants to the debate applying it only as a reaction to the counter candidate's affirmations or gestures. Important declarations and threat/warning do not register significant fluctuations, although with regard to these two indicators Sarkozy manages to record higher values of 58.82\% and $55.55 \%$.

Conversely, in the case of gestures made with the index finger by Ségolène Royal all the functions are identified, including those of refusal/negation and uniqueness, which are absent in her counter candidate's situation.

In the case of specification and drawing attention to oneself, Nicolas Sarkozy dominates the debate with $62.29 \%$ and $80 \%$, with easily identifiable moments when this fact becomes clear even at the level of their declarations. 


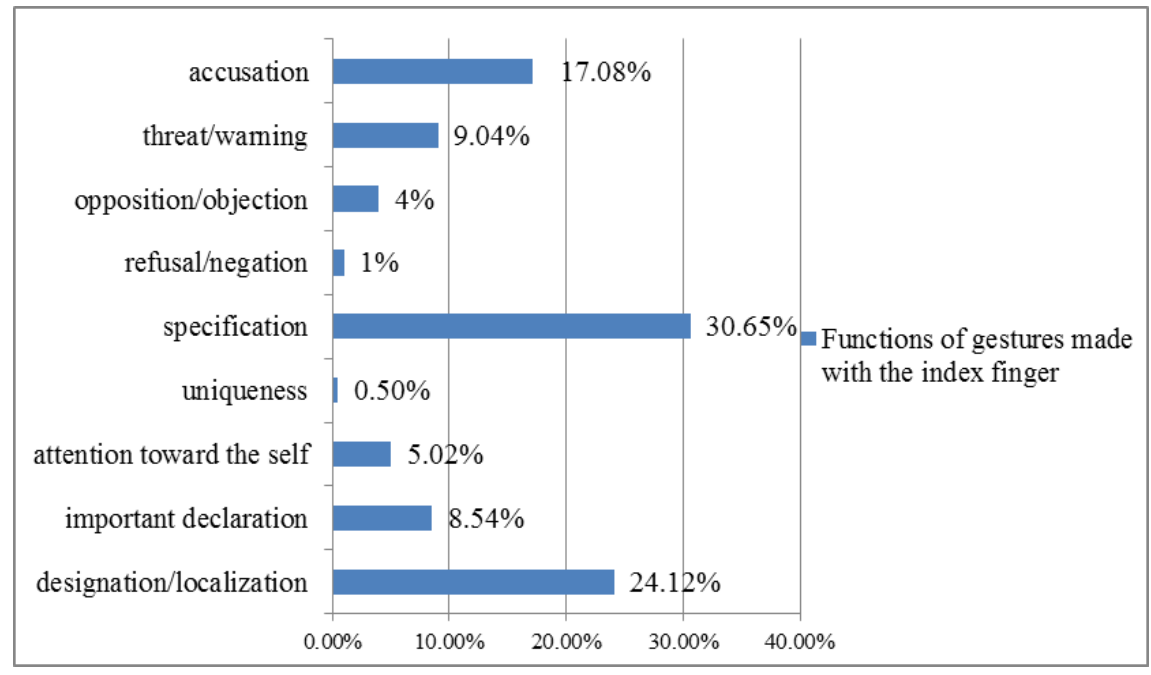

Figure 5. Weighting of functions of gestures made with the index finger during the debate between Royal and Sarkozy

The use of functions of gestures with the index finger in the course of the debate between Ségolène Royal and Nicolas Sarkozy is unequal if we refer to their quantification in percental values. Only three functions stand out with a percentage of over 10\%: specification (30.65\%), designation/localization (24.12\%) and accusation (17.08\%).

Almost equal figures are registered in the case of indicators like threat/warning (9.04\%) and important declaration (8.54\%) on the one hand, and drawing attention to oneself (5.02\%) and opposition/objection on the other hand (4\%), while the rest of the functions range between $1 \%$ (refusal/negation) and $0.5 \%$ (uniqueness).

According to Ch. Delporte (2014), in the French press Ségolène Royal was appreciated as being "very combative", unlike Nicolas Sarkozy, who was considered as "too calm" (Le Figaro), while the entire debate was described as "tense and abounding in irony” (La Corix) or that it "respected its promises” (Les Échos). After the debate, the press did not designate any winner, preferring to wait for the publication of opinion polls instead. The confrontation between the two candidates to the presidency of France appealed to the French, a large number of people watching it on TV (20.1 million people, with 3.3 million people more than in 1995). However, the real audience figures recorded were certainly higher, the debate being rebroadcast by other channels besides TF1 and France 2 (BFM-TV, i-Télé, LCP, France 24, with simultaneous translation in English and Arab) and transmitted by the radio (FranceInfo, RTL, Europe 1) or Internet sites (Arte, for instance, gathered 46.000 Internet users). The francophone viewers were added to them (300.000 Belgians), a fact which made prominent the interest of the public for the stake of the French presidential elections.

\section{Conclusions}

According to the opinion poll conducted in the evening of May 2 by the Opinion Way Institute for Le Figaro and La Chaîne Info and made public on May 3, the debate 
contributed to consolidating Sarkozy's position. The poll was conducted online on a sample of 878 persons (out of the 1,415 initially selected using Quota), who watched the televised debate (source: http://tempsreel.nouvelobs.com/politique/elections2007/20070503.OBS5364/). The confrontation between the two candidates took place at a particular moment of the campaign, when Sarkozy was ascending "slowly but irresistibly" (Delporte, 2014) in the electorate's voting intentions (51-52\% corresponding to 22-26 April and 52-53.5\% for the period between 30 April and May 2). Immediately after the poll was published, Ségolène Royal's campaign directors denounced the "reliability" of the survey, which was associated with mere "control operations".

In the first round, $51 \%$ of the electors of the candidate proposed by the Union for French Democracy, François Bayrou (18.57\%), considered Sarkozy as being "more convincing”, as compared to 35\% for Ségolène Royal, while $24 \%$ considered neither of them as convincing. $74 \%$ of the electors of the candidate proposed by the National Front, Jean-Marie Le Pen (10.44\%), saw Nicolas Sarkozy as more convincing compared to $10 \%$ in Ségolène Royal's favour and $15 \%$ for neither candidate. The most important moment of the debate was, for $55 \%$ of the respondents, the discussion on the theme of disabled children, whereas among the themes mentioned spontaneously we find nuclear energy in the first position with $8 \%$, which also turned out to be the occasion for a very hot exchange of ideas, followed by education (7\%) and pensions (6\%).

With regard to the themes discussed, Ségolène Royal was more persuasive when they debated aspects concerning the environment (53\% compared to $21 \%$ ), the status of disabled children in schools (47\% compared to 30\%), the reduction of social inequality ( $46 \%$ compared to $27 \%$ ), or the situation of schools (45\% compared to $36 \%)$, whereas Nicolas Sarkozy was more convincing in matters of immigration control (65\% compared to 13\%), fighting against insecurity (60\% compared to $17 \%$ ), supporting economic growth (53\% compared to 24\%) or the future of the pension system (52\% compared to $23 \%$ ). The candidates scored equally (35\%) in the debate concerning the future of the medical system.

After the debate, $52 \%$ of the respondents favoured Nicolas Sarkozy as winner of the elections (as compared to $48 \%$ before the debate), whereas 37\% favoured Ségolène Royal (as compared to $36 \%$ before the debate).

Drawing a parallel between the functions of gestures made with the index finger in view of their positive or negative connotations, we can conclude that, even though Ségolène Royal makes fewer gestures in comparison with her counter candidate, she uses them in more than $50 \%$ of the cases in order to exercise her attack strategies. On the other hand, in Nicolas Sarkozy's case, gestures with negative connotations scored a lower percentage of $17 \%$, a fact that could confirm his prudent behaviour in his confrontation with a female candidate.

\section{References}

Agabrian, M. (2006), Analiza de conţinut, Iaşi, Polirom

Ballet, M. (2014), Émotions et élections. Les campagne présidentielles françaises (1981-2012), Paris, INA Éditions

Calbris, G. (1979), «L'index signifiant », in Études de linguistique appliquée. Mélange de didactique des langues, no. 35, juillet-septembre, Paris, Didier Érudition, pp. 91-109

Calbris, G. (2003), L'expression de la pensée d'un homme politique, Paris, CNRS Éditions 
Chelcea, S. (2001), Metodologia cercetării sociologice: metode cantitative şi calitative, Bucureşti, Editura Economică

Delporte, Ch. (présentés par) (2012), Les grands débats politiques. Ces émissions qui on fait l'opinion, Paris, Flammarion et Institut national de l'audiovisuel

El Khamissy, R. (2010), «L'identité visuelle d'un homme politique », in Thélème. Revista Complutense de Estudios Franceses, vol. 25, pp. 83-92

*** «Un sondage réalisé après le débat Royal-Sarkozy crée la polémique », available at http://tempsreel.nouvelobs.com/politique/elections 2007/20070503.OBS5364/un-sondage-realise-apres-le-debat-royal-sarkozy cree-la-polemique.html 